\title{
Long non-coding RNA AGER-1 functionally upregulates the innate immunity gene AGER and approximates its anti-tumor effect in lung cancer
}

\author{
Zihua Pan ${ }^{1,2}$ | Li Liü ${ }^{2}$ | Wenjing Nie $^{2}$ | Sinead Miggin ${ }^{3}$ | Fuman Qiu ${ }^{2}$ | \\ $\mathrm{YiCao}^{2}$ | Jinbin chen ${ }^{2}$ | Binyao Yang ${ }^{2}$ | Yifeng Zhou ${ }^{4}$ | Jiachun Lu ${ }^{1,2}$ | \\ Lei Yang ${ }^{1,2}$ (iD
}

\begin{abstract}
1 The State Key Lab of Respiratory Disease, The First Affiliated Hospital of Guangzhou Medical University, Yuexiu District, Guangzhou, P.R. China

2 The State Key Lab of Respiratory Disease, The Institute for Chemical Carcinogenesis, Collaborative Innovation Center for Environmental Toxicity, Guangzhou Medical University, Xinzao, Panyu District, Guangzhou, P.R. China

${ }^{3}$ Department of Biology, Maynooth University, Maynooth, Ireland

${ }^{4}$ Department of Genetics, Medical College of Soochow University, Suzhou, P.R. China
\end{abstract}

\section{Correspondence}

Lei Yang, MD, PhD, The State Key Lab of Respiratory Disease, The First Affiliated Hospital of Guangzhou medical university, The Institute for Chemical Carcinogenesis, Collaborative Innovation Center for Environmental Toxicity, Guangzhou Medical University, Xinzao, Panyu District, Guangzhou 511436, P.R. China.

Email: leiyang@gzhmu.edu.cn

\section{Funding information}

National Natural Scientific Foundation of China, Grant numbers: 81402753 , 81672303, 81473040, 81673267; Guangzhou Science and Technology Program Pearl River Nova Projects, Grant number: 201710010049; Guangdong Education Bureau Characteristic Innovation Project, Grant number: 2015KTSCX116; Guangdong Provincial Major Projects Grants, Grant number: 2014KZDXM046
Little is known about long non-coding RNA (IncRNA) related to innate immunity in lung cancer. The advanced glycosylation end-product specific receptor (AGER) belongs to the immunoglobulin superfamily, and currently, is the only innate immune pattern-recognition receptor whose abnormal expression has been detected in lung cancer. We aimed to explore the IncRNA that is related to AGER and test its effect on lung carcinogenesis. We selected one IncRNA whose chromosome location is in close proximity to AGER namely Inc-AGER-1 (defined as IncAGER). The expression of IncAGER was tested in 276 pairs of lung cancer tissues and adjacent lung normal tissues, and its correlation with lung cancer clinical progress was analyzed. A series of assays were further used to assess the biological function of IncAGER on lung cancer development, tumor immunity and autophagy. LncAGER expression was moderately correlated with AGER expression ( $r=0.360$, $P=2.15 \times 10^{-18}$ ) underlying a mechanism that IncAGER upregulates AGER by competitively binding to miRNA-185. LncAGER was significantly down-regulated in 76.4\% of lung cancer tissues compared to adjacent normal tissues due to promoter hypermethylation. Over-expression of the IncRNA resulted in significant decreases in proliferation rate, migration ability, colony formation efficiency of lung cancer cells and tumor growth in nude mice. Notably, IncAGER possibly conduced to enhancement of cytotoxic effect of THP1. Additionally, the IncRNA also promoted cell apoptosis by strengthening autophagy. Taken together, these observations suggest that IncAGER has an inhibitory effect on lung cancer development via AGER, which may serve as a target for lung cancer treatment.

\section{KEYWORDS}

autophagy, cytotoxic effect, lung cancer treatment

Abbreviations: AGER, advanced glycosylation end-product specific receptor; CCK8, cell counting kit-8; ceRNA, competing endogenous RNA; IncRNA, long non-coding RNA; PPR, pattern-recognition receptor; TLR, toll-like receptor. 


\section{1 | INTRODUCTION}

Lung cancer has been the leading cause of cancer-related deaths for several years, attributed to about 610200 deaths in China in 2015 and expected to be attributed to 155870 deaths in America in 2017. ${ }^{1,2}$ In recent decades, the treatment strategies for lung cancer have developed greatly, which effectively improved the 5-years' survival rate of lung cancer ranging from $8 \%$ at $1995-1999$ to $18 \%$ at 2005 2009. ${ }^{3}$ However, there is still a great need for alternative treatment strategies for treating lung cancer, as the 5-years' survival rate is below $20 \%$. Immunotherapy is currently a white hope for oncotherapy, yet emerging data suggests that the immuno checkpoint inhibitors such as programmed death 1 (PD-1)/programmed death ligand 1 (PD-1/PDL1) inhibitors show promise towards improving the survival time of lung cancer patients. ${ }^{4-6}$ The Food and Drug Administration (FDA) have approved two anti-PD-1 monoclonal antibodies for treating lung cancer, however in response to the therapy, resistance to the drugs has increasingly been observed. ${ }^{7,8}$ Thus, further studies towards understanding the role of immunity in lung cancer are warranted, given that limited studies in the area have been undertaken as lung cancer was historically recognized as a non-immunogenic disease. Finding critical molecules that modulate immunity in the context of lung carcinogenesis would lead to the exploitation of immunotherapeutic agents.

The innate immune system provides the first line of protection against infectious and non-infectious tissue injury. Environmental carcinogens such as tobacco can induce lung tissue injury and trigger the activation of innate immune system through pattern-recognition receptors (PPRs) including Toll-like receptors (TLRs) and advanced glycosylation end-product specific receptor (AGER, also named receptor for advanced glycation end products, RAGE). ${ }^{9}$ AGER can recognize endogenous molecules released during chronic inflammation, a major contributing factor to the pathogenesis of lung cancer. Notably, it has been shown that pulmonary AGER is required for allergen-induced innate lymphoid cells accumulation in the lung. ${ }^{10}$ Further, AGER is one of a limited number of pathogen-recognition receptors whose expression is altered in lung cancer. ${ }^{11,12}$ Meanwhile, analyzing the public data of lung cancer cohorts namely GSE32863 (https://www.ncbi.nlm.nih.gov/geo/geo2r/?acc=GSE32863), and GS E27262 (https://www.ncbi.nlm.nih.gov/geo/geo2r/?acc= GSE27262) using the GEO2R software, AGER ranks among the top five abnormal coding genes in lung cancer. But for TLRs, their expressions are normal.

Accumulating evidences show that long non-coding RNAs (IncRNAs), non-protein coding transcripts longer than 200 nucleotides, are crucial epigenetic regulators of protein expression and function. Numerous IncRNAs have been identified as being associated with lung cancer. ${ }^{13,14}$ These IncRNAs function as possible oncogenes or tumor suppressors to promote or dampen lung cancer development through several pathological mechanisms such as the epithelial-mesenchymal transition, ${ }^{15}$ the MAPK signaling pathway. ${ }^{16}$ However, little is known about the role of immunity-related IncRNAs in lung cancer.

In the current study, we aimed to explore whether innate immune related IncRNAs are modulated in the context of lung carcinogenesis. Given that IncRNAs may exert their biological functions via regulation of neighbor protein-coding genes, one IncRNA named Inc-AGER-1 (defined as IncAGER here: http://www. Incipedia.org/db/gene/Inc-AGER-1); whose chromosome location (chr6:32,152, 516-32,153,659) is near that of AGER (chr6:32,148, 745-32,152,099), was selected for further investigation in the context of lung carcinogenesis. LncAGER also named XXbacBPG300A18.13 in the UCSC database and is characteristic as a 3prime_overlapping_ncRNA where ditag and/or published experimental data strongly supports the existence of short non-coding transcripts transcribed from the $3^{\prime}$-untranslated region ( $3^{\prime}$-UTR). Our study demonstrated that IncAGER may function to inhibit lung cancer development, suggesting that it may be utilized as a novel therapeutic target in the treatment of lung cancer.

\section{2 | MATERIALS AND METHODS}

\section{1 | Tissue samples}

Two hundred and seventy-six lung cancer tissues and adjacent normal lung tissues were obtained from patients who were diagnosed pathologically as having primary lung cancer. Among these patients, 182 samples from southern China were collected at the Cancer center of Guangzhou Medical University and the 1st Affiliated Hospital and the Cancer Hospital of Kunming Medical University between 2008 and 2015, the other 94 from eastern China were gathered at the 1st Affiliate Hospital of Soochow University between 2007 and 2016. During surgical excision, a portion of putative lung tumor tissues and adjacent normal lung tissues were immediately isolated from the excision and placed in liquid nitrogen tank after washed by phosphate buffer saline (PBS) by a doctor. The samples which considered as tumor tissues or normal tissues were further determined through pathologic examination by two pathologists. A written informed consent was obtained from each patient. The study was approved by the institutional review board at Guangzhou Medical University and Soochow University.

\section{$2.2 \mid$ Cell culture}

All cells used in this study were purchased from Cell Bank of Type Culture Collection of the Chinese Academy of Science (Shanghai Institute of Cell Biology, Shanghai, China) including nine lung cancer cell lines (ie, PC9, L78, A549, GLC-82, SBC-5, 95D, NCl-H460, NCl$\mathrm{H} 292$, and $\mathrm{NCl}-\mathrm{H} 1395)$, four human immortalized lung normal cell lines (ie, 16HBE, HBE-pic, BEAS-2B, and BEP-2D), human embryonic kidney cell (HEK-293), and human monocytic leukemic cell line (THP-1). All cells were cultured in RPMI1640 medium (Gibco, Thermo Fisher Scientific, Waltham, MA) with the exception of HEK-293 which were cultured in DMEM and all media was supplemented with $10 \%$ fetal bovine serum (FBS). Cells were placed in a $\mathrm{CO}_{2}$ incubator (SANYO Electric Co., Ltd., Chuou-ku, Osaka City, Japan) with constant $90 \%$ humidity and $5 \% \mathrm{CO}_{2}$. The lung cells were utilized for IncAGER expression analysis. HEK-293 was used for lentivirus packaging and production and THP-1 was utilized for co-cultivation assays. 


\section{3 | Gene expression detection}

The routine SYBR-green quantitative reverse real-time PCR (qRT-PCR) was performed to assess the expression of IncAGER and AGER in the 276 pairs of lung tissues and 13 cases of lung cell lines with $\beta$-actin used as an internal standard control. The primers for IncAGER were $5^{\prime}$-AAC CAG GAG GAA GAG GAG GA-3' (forward) and 5' -TTG GCA AGG TGG GGT TAT AC-3' (reverse), for AGER were 5'-CTA CCG AGT CCG TGT CTA CC-3' (forward) and 5'-AGT GTG AAG AGC CCT GTC TC-3' (forward) and for $\beta$-actin were $5^{\prime}$-GGC GGC ACC ACC ATG TAC CCT-3' (forward) and 5'-AGG GGC CGG ACT CGT CAT ACT-3' (reverse). The $2^{-\triangle C T}$ method was used to demonstrate the expression levels of InCAGER and AGER. In addition, the standard western blotting analysis was used to test for the protein expression levels of AGER with Tubulin serving as an interval standard control. Notably, the IRDye $800 \mathrm{CW}$ labeled secondary antibodies (LI-COR, Lincoln, NE) were used in combination with the LI-COR Odyssey Infrared Imaging System (LI-COR). Antibodies were purchased from the Abcam Company (Abcam, Shanghai, China) unless indicated otherwise and all assays were repeated at least three times. In addition, the expression of AKT1 and $A B C C 1$ were also determined using the qRT-PCR because they are well-characterized targets of miR-185 involving lung carcinogenesis. ${ }^{17,18}$

\section{4 | Demethylation treatment with 5-Aza-CdR}

On account of that hypermethylation was found to be associated with decreased expression of AGER in lung cancer tissues, ${ }^{19}$ we speculated that promoter methylation may play a role in regulation of both AGER and IncAGER expression. Total $1 \times 10^{5}$ PC9 cells were seeded in a 24-well culture plate and treated with the DNA demethylating agent 5-aza-2-deoxy-cytidine (5-Aza-CdR) at concentrations of $0,0.5,2$, $10 \mu \mathrm{mol} / \mathrm{L}$ for $72 \mathrm{~h}$. Then the cells were collected and prepared for the qRT-PCR analysis to determine IncAGER and AGER expression.

\section{5 | MassARRAY ${ }^{\circledR}$ quantitative methylation analysis}

The MassARRAY ${ }^{\circledR}$ Quantitative Methylation Analysis was conducted to determine promoter methylation level of IncAGER and AGER in 15 paired DNA samples from lung cancer tissues and adjacent normal lung tissues by a commercial company (Biomiao Biological Technoiogy, Beijing, China). As cpgplot (http://www.ebi.ac.uk/Tools/seqstats/ emboss_cpgplot/) shows no CpG island in promoter region of both IncAGER and AGER, promoter regions with high density CG sites in InCAGER ( -868 to -1313 bp relative to transcriptional start site) and AGER ( -984 to -1584 bp relative to transcriptional start site) were tested. The Agena EpiDesigner was used to designed primers for IncAGER as "forward: aggaagagagGAAGGTTTTTAAATTTGTGTGT GG" and "reverse: cagtaatacgactcactatagggagaaggctACTCCTATTACAACCTCCCAACTTC"; for AGER as "forward:aggaagagagATTTTTGGATAGAGGATATGGGTTA" and "reverse: cagtaatacgactcactataggga gaaggctAACAAACCCTTCACTACCTCCAC". The methylation rate was calculated from 15 pairs of lung cancer and adjacent normal tissues and the frequency of methylation level was defined as the average methylation rate of tumor or normal tissues.

\subsection{Construction of the lentivirus vector of IncAGER and infection}

The full-length complementary DNA (cDNA) of human IncAGER was synthesized by iGeneBio Co, Ltd (Guangzhou, China). The cDNA was then cloned into the lentivirus vector $p E Z-L v 201$. The IncAGER vector or the empty vector were transfected into HEK-293 to collect viral particles. The viral particles were then used to infect two lung cancer cell lines, PC9 and L78, which express extremely low IncAGER followed by qRT-PCR to analyze the expression of IncAGER to determine the infection success rates. Cells expressing the correct levels of IncAGER were used for further studies. Cells that were infected with empty pEZ-Lv201 particles were used as control cells.

\section{7 | MicroRNA mimics treatment and luciferase assay}

Given that bioinformatics analysis (http://www.mirbase.org/index. shtml, http://www.microrna.org/microrna/getMirnaForm.do) showed that IncAGER may function as a competing endogenous RNA (ceRNA) to promote AGER expression by binding to microRNAs miRNA-46885p, miRNA-3171, miRNA-185, and miRNA-182, the mimics or inhibitors of these microRNAs were synthesized and transiently cotransfected with the Psi-CHECK2 luciferase reporter containing the $3^{\prime}$-UTR of AGER into the PC9 and L78 cell lines. Luciferase activity that is defined as renilla luciferase data normalized to firefly luciferase data was then determined using the Dual-Luciferase Reporter Assay System (Promega, Beijing, China). Independent triplicate experiments were performed using each microRNA. In addition, the two cell lines were also directly treated with the miRNA-185 mimics to determine the effect of microRNA on AGER expression. The suppression rate of AGER expression was calculated by the ratio of AGER protein level following miR-185 treatment minus normal AGER protein level to normal AGER protein level.

\subsection{Subcellular fractionation}

To establish the subcellular localization of IncAGER, cytosolic and nuclear fractions were isolated using the nuclear/cytoplasmic isolation kit (Biovision, San Francisco, CA). Following total RNA extraction from the cytosolic and nuclear fractions, gene expression analysis was performed by the qRT-PCR.

\section{9 | Tumor cell viability and proliferation assay in vitro}

The cell counting kit-8 (CCK8) assay, plate colony and soft-agar colony forming experiments were performed to assess the effect of IncAGER on viability and proliferation of PC9 and L78 cells, in accordance with the manufacturer's protocols. In the CCK8 assay, cells were cultured in 
a 96-well plate with 1000 cells per well and the cell viability was monitored after $24,48,72$, and $96 \mathrm{~h}$. In the plate colony experiment, the cells were plated in a 6-well plate at a density of 1000 cells each group and cultured for two weeks. After stained with Giemsa, the visible colonies were counted (The whole plate was divided into nine sub-boxes and total clones were counted in settled six representative fields). In the soft-agar experiment, the lower layer agar contained $5 \mathrm{~mL}$ of $0.75 \%$ low melting agar in RPMI-1640 medium with $10 \% \mathrm{FBS}$, while the upper second layer containing $0.35 \%$ agar dissolved in RPMI1640 medium with $10 \%$ FBS in a $60 \mathrm{~mm}$ dish. When solidified, the upper layer was injected with 1000 cells. After cultured for $3 \mathrm{wk}$, the dishes were stained with $0.04 \%$ crystal violet (Sigma, Guangzhou, China) and the colonies were counted (The whole plate was divided into 16 sub-boxes and total clones were counted in settled eight representative fields). All trials were conducted at least three times.

\subsection{0 | Flow cytometry analysis}

The flow cytometry analysis was used to establish whether IncAGER had an effect on cell cycle and apoptosis. For cell cycle analysis, PC9 and $\mathrm{L} 78$ cell lines were labeled with propidium iodide (PI) (7seapharmtech, Shanghai, China). For analysis of apoptosis, the Annexin Vfluorescein isothiocyanate/7-Aminoactinomycin D (FITC/7-AAD) apoptosis kit was used according to the manufacturer's construction (MULTISCIENCES, Hangzhou, China).

\subsection{1 | Tumor cell migration and invasion assay}

An 8- $\mu$ m Transwell chamber (Costar, Corning Incorporated, Corning, NY) without or with matrigel-coated was used to test cell migration and invasion of the PC9 and L78 cell lines. The protocols were performed in accordance with our previously published studies. ${ }^{20}$ Briefly, $1.0 \times 10^{5}$ cells were plated on Transwell chambers with $20 \mathrm{mg}^{\text {Matrigel }}{ }^{\mathrm{TM}}$ or uncoated. The lower chamber contained medium with 10\% FBS which served as the chemoattractant. Non-invading or non-migrated cells were removed with cotton swabs, and migrated or invaded cells were counted (total cells were counted in randomly selected twenty representative fields). Each experiment was performed in triplicate.

\subsection{2 | Tumor growth in vivo}

The PC9 and L78 cell lines were diluted to a concentration of $1 \times 10^{6}$ cells/ $\mathrm{mL}$ in phosphate buffer (PBS). Then, $0.2 \mathrm{~mL}$ of the cell solution $\left(2 \times 10^{5}\right.$ cells) were subcutaneously injected into BALB/c nude mice ( $n=5$ per group). The volume of tumor was calculated as length $\times$ width ${ }^{2} \times 0.5$. After 24 days, the mice were euthanized and the lung solid tumors were isolated for pathological section analysis. The expression of AGER and lung tumor morphology were investigated by immunohistochemical staining and morphometric technique using established routine procedures. In scoring AGER protein expression, the Image Pro Plus software was used to measure staining intensity score following the standard protocol. Percentage of positive cells examined was scored as 0 (negative), 1 (<10\%), 2 (11-50\%), 3 (51-80\%), and 4 (>80\%) by two independent pathologists. The relative AGER expression was defined as the intensity score multiplying the percentage score.

\subsection{Co-culture of monocyte and lung cancer cells}

To explore the possible role of IncAGER on tumor immunology, PC9 or L78 cell line was co-cultured with the human monocyte cell line THP-1 (ie a suspension cell line, effector cells). THP-1 cells were initially seeded with a concentration of $2 \times 10^{5}$ cells $/ \mathrm{mL}$ per well in a 96-well plate. After $24 \mathrm{~h}$, either PC9 or L78 cells were added to each well (1000 cells per well, targeted cells). The lung cells were also independently cultured and served as control groups. After $24 \mathrm{~h}$, the cell supernatants (in the presence/absence of THP-1 cells) and lung cancer cells were collected to determine optical density (OD) using the CCK8 assay. The cytotoxic activity of THP1 was calculated as follows: ${ }^{21}$

$$
\text { Cytotoxicity }=\frac{1-(\mathrm{OD} \text { effector cells }+ \text { target cells })-(\mathrm{OD} \text { effector cells })}{\text { OD target cells }}
$$$$
\text { as suggested. }
$$

\subsection{4 | Autophagy detection}

Autophagy is known as programmed type II cell death, which plays an essential role in development, organization, and functions of the immune system. Defects in autophagy lead to several diseases, including cancer and autoimmunity. ${ }^{22}$ Here, autophagy level was determined in terms of the ratio between LC3-II protein expression and LC3-I protein expression. The routine western blotting analysis was used to test for the protein expression levels of both LC3-II and LC3-I with Tubulin serving as an interval standard control.

\subsection{5 | Statistical analysis}

The paired $t$-test was used to assess the differences in gene expression and frequency of methylation level between lung cancer tissues and adjacent lung normal tissues. The student's $t$-test and one-way Anova test were applied for analyzing the differences in quantitative data between two groups. The Pearson correlation analysis was performed to analyze correlation between two the quantitative data. All tests were two-sided by using the Stata 12.0 software and $P$-value less than 0.05 was considered to be statistically significant.

\section{3 | RESULT}

\subsection{LncAGER is down-regulated in lung cancer}

Both the Coding Potential Calculator (http://cpc.cbi.pku.edu.cn/) and the Coding-Potential Assessment Tool (http://lilab.research. bcm.edu/cpat/index.php) strongly suggested that IncAGER has no coding probability. As shown in Figure $1 \mathrm{~A}$, the expression of IncAGER was significantly lower in lung cancer tissues when compared to adjacent lung normal tissues in southern samples 

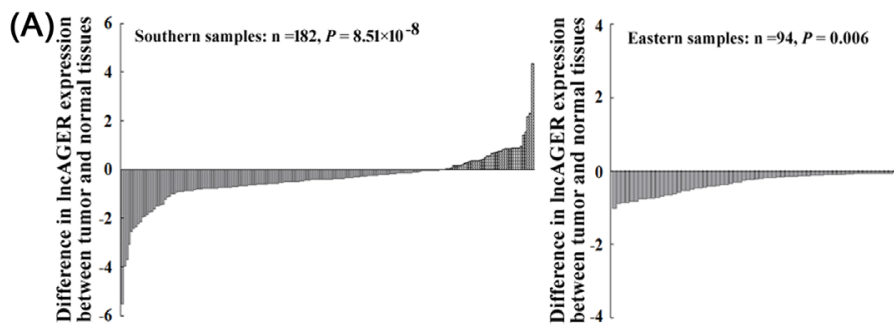

(C)

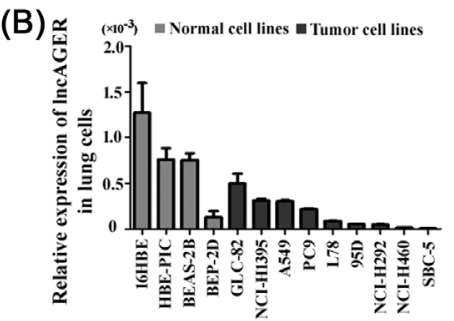

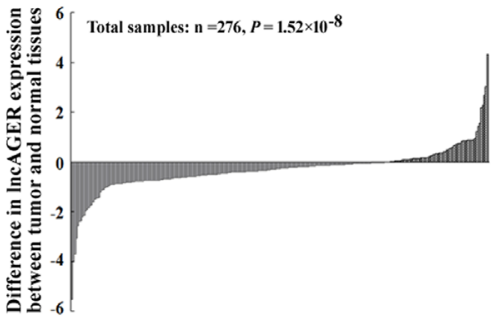

(D)

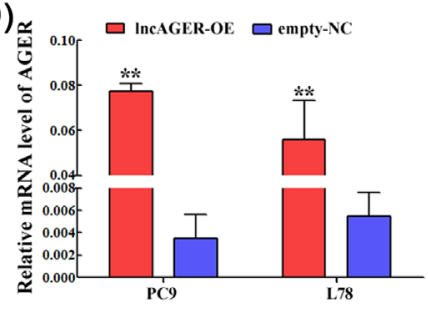

(E)

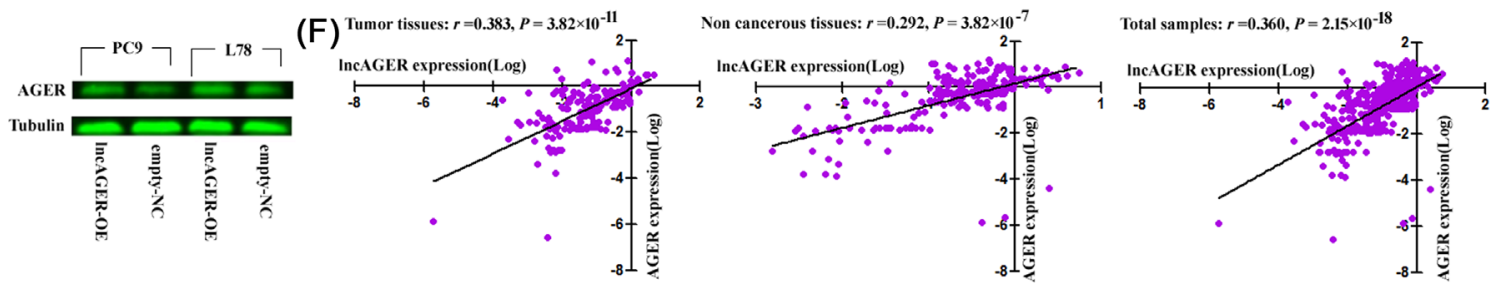

FIGURE 1 Expression status of IncAGER and AGER and their correlation in lung tissues. (A) The qRT-PCR was performed to assess the expression of IncAGER in lung tissues from southern samples (left), eastern samples (middle) and total samples (right). Bar height corresponds to the log mean difference between tumor tissues and normal tissues from three technical replicates. $P$, calculated by the paired $t$-test. (B) The expression of IncAGER in lung cancer and normal cell lines. (C) Subcellular localization of IncAGER expression. (D) The qRT-PCR was conducted to determine AGER mRNA expression. Bar height corresponds to the mean, and error bars represent SD for three biological or technical replicates. ${ }^{* *} P<0.01$, calculated by the student's $t$-test. $(E)$ The western blot was conducted to determine AGER protein level. ( $F$ ) The correlation between IncAGER expression and AGER expression in lung cancer tissues (left), in adjacent normal lung tissues (middle) and in total lung tissues (right). Purple dot corresponds to log IncAGER expression in $x$ axis and log AGER expression in $y$ axis. $P$, calculated by the Pearson correlation analysis

(mean \pm standard deviation: $0.29 \pm 0.53$ vs $0.70 \pm 0.79$; $\left.P=8.51 \times 10^{-8}\right)$, eastern samples $(0.19 \pm 0.52$ vs $0.27 \pm 0.51$; $P=0.006)$ and total samples $(0.26 \pm 0.53$ vs $0.57 \pm 0.69$; $\left.P=1.52 \times 10^{-8}\right) ; 76.4 \%(211 / 276)$ of the lung cancer samples showing a downregulation of IncAGER. A similar trend was also observed in lung cell lines when compared to normal cells wherein the normal cells showed higher IncAGER than the cancer ones (Figure 1B). In addition, the lentiviral vector carrying IncAGER was successfully constructed and high expression of IncAGER in both the PC9 and L78 cells was evident (Figure S1a). In addition, the expression of AGER was significantly down-regulated in cancer tissues compared to their adjacent normal tissues $(P<0.001$; Figure $S 1 b-d)$, which are concordant with previously published studies. ${ }^{11,12}$ The demographics and clinical feathers of studied patients are listed in Table 1.

\subsection{IncAGER expression is correlated with T status}

The expression status of IncAGER was classified as "High" or "Low" on the basis of whether or not owing to the expression of IncAGER in lung tissues upon in adjacent lung normal tissues. As listed in Table 2, patients with advanced $T$ status $(3+4)$ exerted significantly more low status of IncAGER expression than those with early T status $(1+2)$ in southern samples ( $15.4 \%$ vs $31.7 \% ; P=0.033$ ). The difference was towards a margin at the edge of significance in eastern samples $(22.4 \%$ vs $48.9 \% ; P=0.061$ ). When merged the two populations, low expression of IncAGER was associated with risk of advanced T status $(P=0.002)$. However, there was no other notable association between IncAGER expression and other variables.

\subsection{IncAGER enhances AGER expression via binding to miR-185}

Both PC9 and L78 expressed a relevant portion of IncAGER in cytoplasm (Figure $1 \mathrm{C}$ ), indicating a role of IncAGER as a posttranscriptional factor. The cells that overexpressed IncAGER showed a significantly higher level of AGER expression than that of control cells at both mRNA and protein levels (Figures 1D and 1E). Meanwhile, the expression of IncAGER was positively correlated with that of AGER in lung cancer tissues $(r=0.383$, 
TABLE 1 The demographics and clinical feathers of studied lung cancer patients

\begin{tabular}{|c|c|c|c|c|}
\hline Characteristic & Southern samples $N(\%)$ & Eastern samples $N(\%)$ & Pearson $\chi^{2}$ & $P$-value \\
\hline Total & $182(65.9)$ & $94(34.1)$ & & \\
\hline \multicolumn{5}{|l|}{ Age } \\
\hline$\geq 60$ & $77(42.3)$ & $43(45.7)$ & & \\
\hline \multicolumn{5}{|l|}{ Gender } \\
\hline Male & $130(71.4)$ & $66(70.2)$ & & \\
\hline \multicolumn{5}{|l|}{ Family tumor history } \\
\hline No & $161(88.5)$ & $84(89.4)$ & 0.050 & 0.822 \\
\hline Yes & $21(11.5)$ & $10(10.6)$ & & \\
\hline \multicolumn{5}{|l|}{ Stage } \\
\hline$I+I I$ & $71(39.0)$ & $29(30.9)$ & 1.786 & 0.181 \\
\hline III + IV & $111(61.0)$ & $65(69.1)$ & & \\
\hline \multicolumn{5}{|l|}{$T$} \\
\hline $1+2$ & $104(57.1)$ & $45(47.9)$ & 2.145 & 0.143 \\
\hline $3+4$ & $78(42.9)$ & $49(52.1)$ & & \\
\hline \multicolumn{5}{|l|}{ N } \\
\hline 0 & $76(41.8)$ & $57(60.6)$ & 2.332 & 0.127 \\
\hline $1+2+3$ & $106(58.2)$ & $37(39.4)$ & & \\
\hline Squamous carcinoma & $51(28.0)$ & 31 (33.0) & & \\
\hline Other types ${ }^{a}$ & $45(24.7)$ & $22(23.4)$ & & \\
\hline
\end{tabular}

aLarge cell carcinoma, small cell carcinoma, and hybrid or undifferentiated carcinoma.

$\left.P=3.82 \times 10^{-11}\right)$, normal tissues $\left(r=0.292, P=3.82 \times 10^{-7}\right)$, and in total tissues $\left(r=0.360, P=2.15 \times 10^{-18}\right.$; Figure $\left.1 \mathrm{~F}\right)$. Further analyses showed that IncAGER may regulate AGER expression by binding to miRNA-185. Bioinformatic analysis predicted that 4 microRNAs are expressed in both PC9 and L78 cells (Figure S2a) and of these, the luciferase assay showed that miR-185 (Figure 2A), but not miR-182, miR-3171, or miR-4688-5p (Figure S2b-d) could possibly bind to $3^{\prime}$-UTR of AGER, as that miR-185 mimics significantly weakened the luciferase activity, while the inhibitors enhanced it $(P<0.05$ for all). The miR-185 mimics caused significantly less reduction of luciferase activity in both cells overexpressed IncAGER than control cells, but the inhibitors resulted in non-significant increase between the up-regulated and control cell lines (Figure 2B). Further, following treatment of PC9 or
L78 cells with the miR-185 mimics, the AGER protein expression was not suppressed to the same level in cells overexpressing IncAGER when compared to control cells (Figure 2C).

\subsection{IncAGER prevents suppression effect of miR- 185 on $A K T 1$ and ABCC1}

Following treatment of PC9 cells with the miR-185 mimics or mock mimics, miR-185 apparently did not alter expressions of both AKT1 and $A B C C 1$ in cells overexpressing InCAGER unlike what it did in control cells to significantly suppress the expression of two genes (Figures 2D and 2E). Noticeably, expressions of both AKT1 and ABCC1 were still down-regulated in cells overexpressing IncAGER when compared to control cells. 
TABLE 2 Associations between the expression of IncAGER and clinical feathers as well as demographics among lung cancer patients

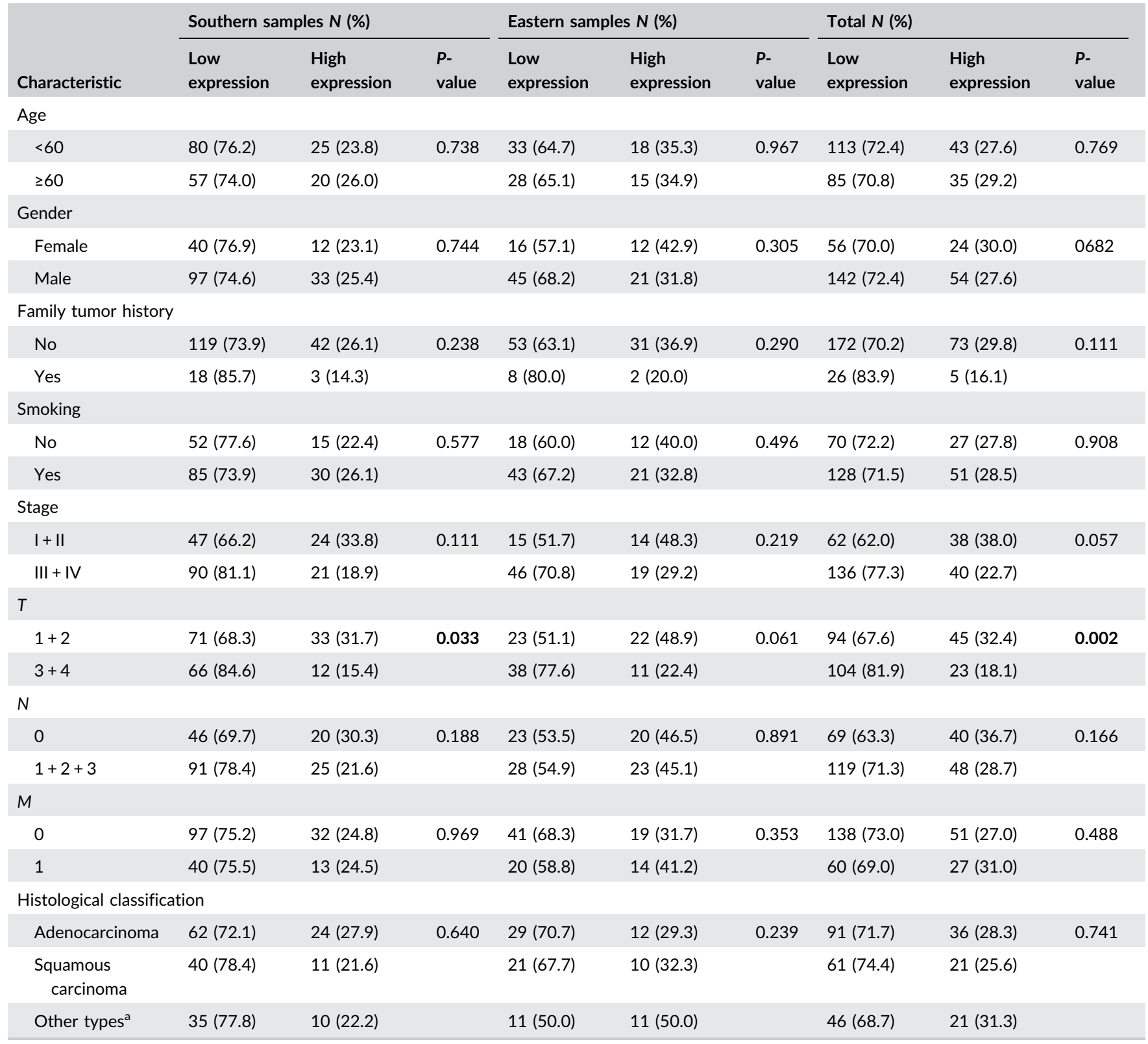

atarge cell carcinoma, small cell carcinoma, and hybrid or undifferentiated carcinoma.

Bold font indicates significant difference.

\section{5 | Promoter methylation directly contributes to decreased IncAGER but not AGER expression}

After treatment of PC9 cells with 5-Aza-CdR, IncAGER expression increased sequentially along with increase of 5 -Aza-CdR concentration $(P=0.012$; Figure $2 F)$. A similar trend was observed on AGER expression. However, the effect was not significant $(P=0.704$; Figure S3a). The MassARRAY further showed that cancer tissues harbored a significantly higher methylation level at promoter region of IncAGER than normal tissues (Figure 2G). However, no significant difference was observed for AGER (Figure S3b, c). Moreover, the average methylation level of IncAGER promoter was negatively correlated with IncAGER expression $(P=0.004$; Figure $2 \mathrm{H})$.

\subsection{IncAGER inhibits proliferation and tumor growth of lung cancer cells}

Using the CCK8 assay, it was shown that the proliferation of cells expressing IncAGER was significantly lower when compared to the control groups (Figure 3A). Similarly, both the plate colony and softagar experiments showed that the up-regulation of IncAGER impaired the tumorigenesis abilities of both the PC9 and L78 cell lines in vitro (Figures $3 \mathrm{~B}$ and $3 \mathrm{C}$ ). The findings were corroborated with our in vivo work which showed that IncAGER inhibited tumorigenesis in nude mice. As shown in Figure 3D, the tumors were smaller and slower to develop in mice, which were injected with the cells that overexpressed IncAGER when compared to control cells. Meanwhile, the 
(A)

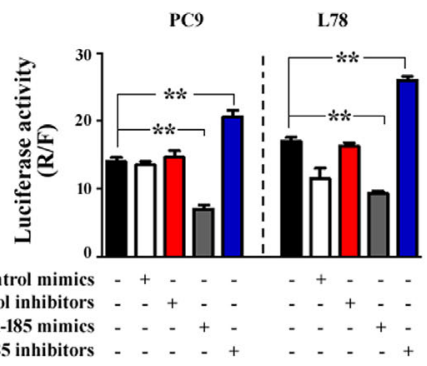

(D)

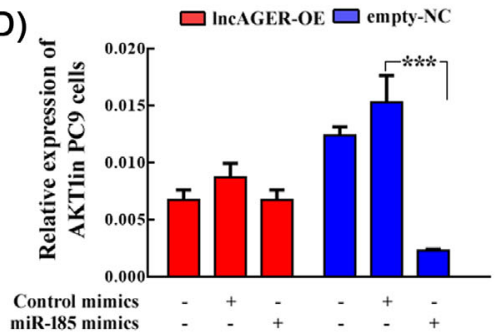

(B)

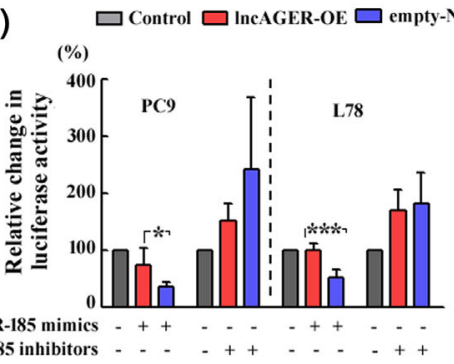

$(\mathrm{E})$

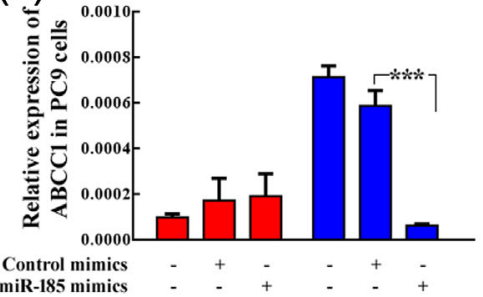

(C)

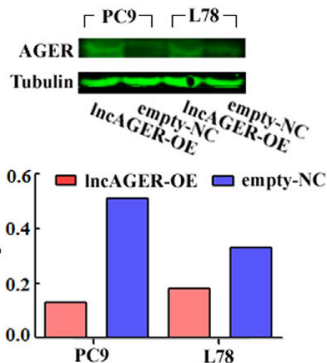

$(\mathrm{F})$

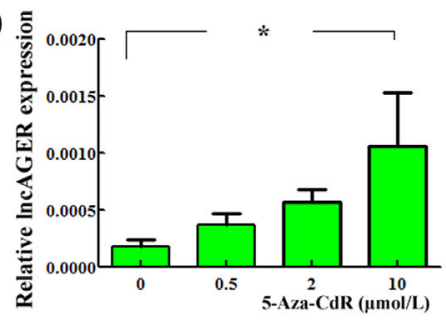

(G)

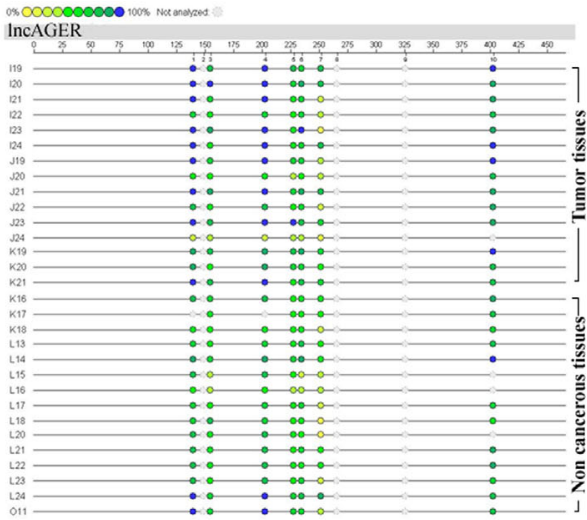

(H)

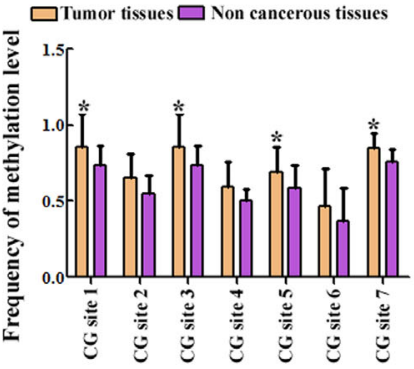

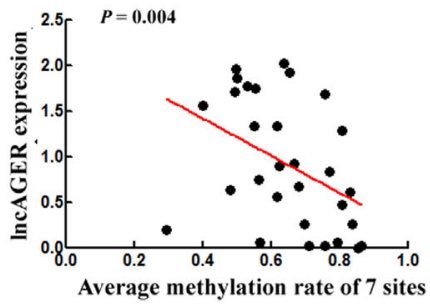

FIGURE 2 Regulatory mechanisms of IncAGER on expression of target genes and IncAGER down-regulation. (A) The luciferase assay was conducted to determine effect of miR-185 on 3'-UTR of AGER in PC9 and L78 cells. R/F: Renilla luciferase data normalized to firefly luciferase data. (B) The luciferase assay in IncAGER overexpression cells and control cells of PC9 and L78. (C) AGER protein level in IncAGER overexpression cells and control cells of PC9 and L78 following treatment of miR-185 mimics. The suppression rate of AGER expression was calculated by the ratio of AGER protein level following miR-185 treatment minus normal AGER protein level to normal AGER protein level. (D and E) Expression of AKT1 (D) and ABCC1 (E) in IncAGER overexpression cells and control cells of PC9. (F) Expression of IncAGER in PC9 cells following 5- Aza-CdR treatment. Bar height corresponds to the mean, and error bars represent SD for three biological or technical replicates. $P$-value was calculated by the student's $t$-test or oneway Anova test. (G) Methylation analysis by the MassARRAY. Left: Circle indicates methylation level of each CG site. The darker the color represents the higher the methylation rate (left). Methylation level was calculated from 15 pairs of lung cancer and adjacent normal tissues and the frequency refers to the average methylation rate of tumor or normal tissues (right). $P$-value was calculated by the paired $t$-test. $(H)$ Correlation between average methylation level of $7 \mathrm{CG}$ sites and IncAGER expression. $P$-value was calculated by the Spearman rank correlation analysis. ${ }^{*} P<0.05,{ }^{* *} P<0.01,{ }^{* * *} P<0.001$

pathological characteristics of tumor were more obvious in the latter than the former (Figure 3E). In addition, the tumor tissues originated from overexpressed IncAGER cells expressed higher AGER than that originated from the control cells (Figure 3F).

\subsection{IncAGER suppresses cell migration, but not invasion}

As shown in Figure 4A, the ability of PC9 cells to migrate was impaired in cells which over-expressed IncAGER $(P=0.026)$, however, the invasion ability through Matrige ${ }^{\mathrm{TM}}$ remained unchanged when compared to control cells $(P=0.732$; Figure $4 \mathrm{~B})$. We failed to detect the ability to migrate and invade of $L 78$ cells because no cells pass through the Boyden chambers.

\subsection{LncAGER affects cell cycle and apoptosis}

The flow cytometry data showed that the overexpression of IncAGER induced more cells arrest at G0/G1 phase and concomitantly fewer cells at the $\mathrm{S}$ phase of cell cycle when compared to control cells (Figure 4C). Also, higher rates of apoptosis were evident in cells which overexpressed IncAGER when compared to the control cells (Figure 4D). 
(A)
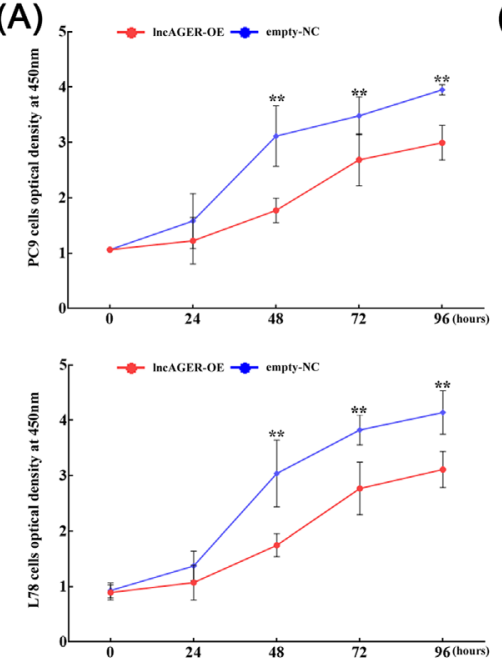

(C)
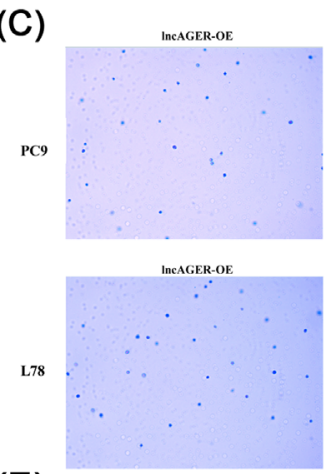

(E)
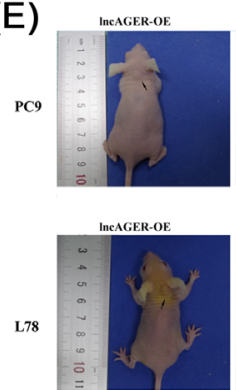
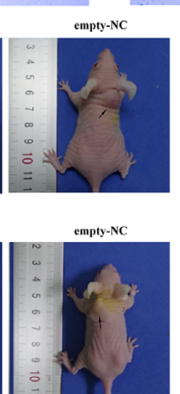

(B)
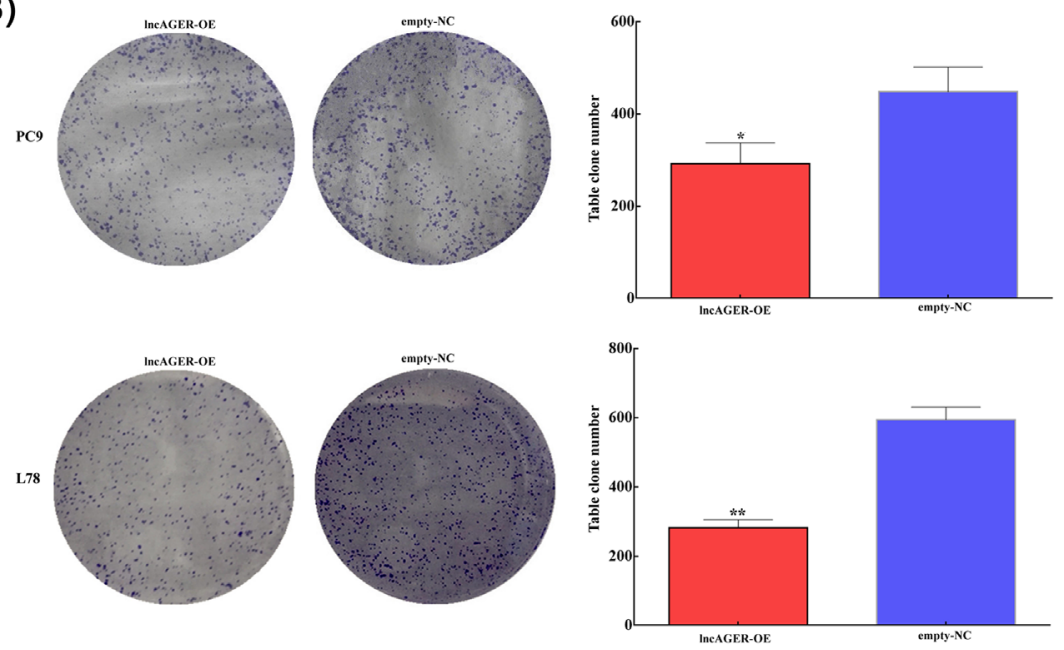

(D)
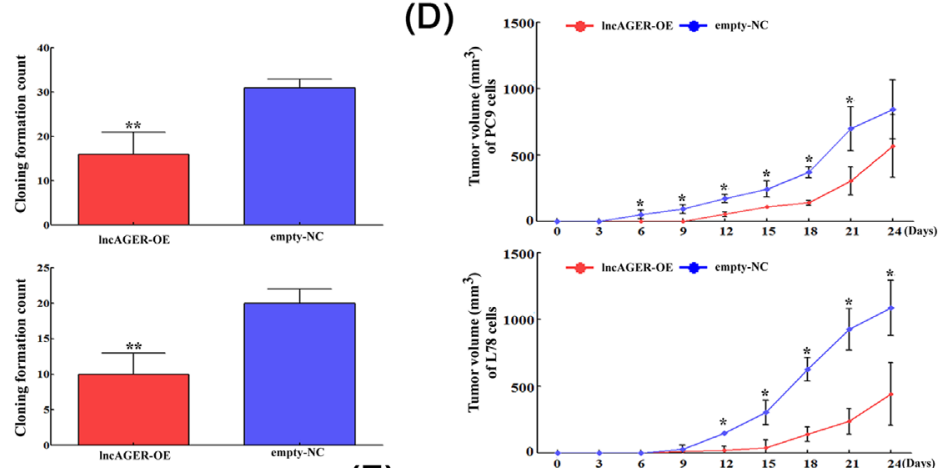

mpty-NC

(F)
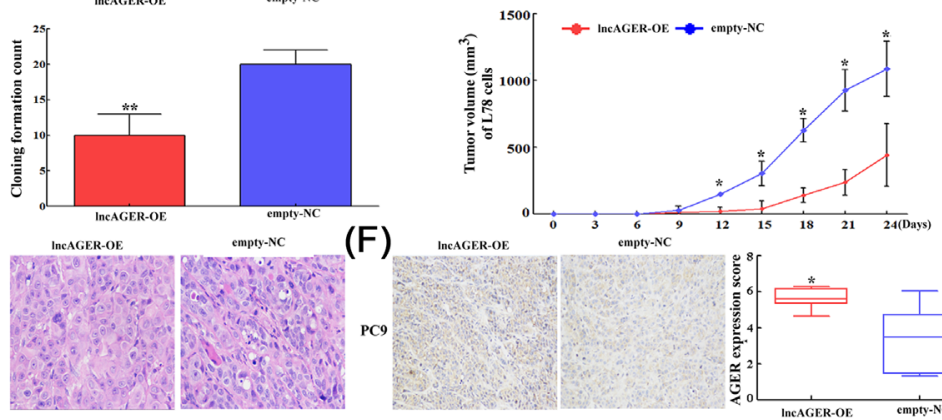

empty-NC

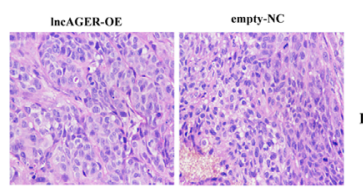

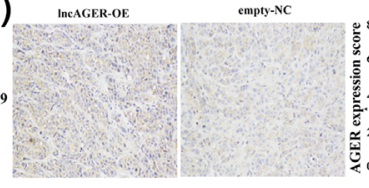

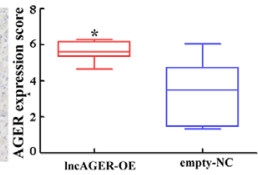

empty-NC
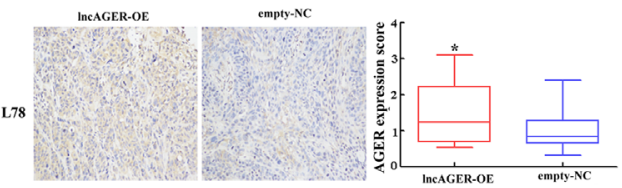

FIGURE 3 Biological effects of IncAGER on tumor growth of lung cancer. Both PC9 and L78 cells were transfected with pEZ-Lv201IncAGER (IncAGER-OE) and empty pEZ-Lv201 (empty-NC). (A) The CCK8 assay was conducted to determine the proliferation of PC9 and L78 cells. Circle dot on line corresponds to the mean, error bars represent SD for seven biological replicates. (B and C) The plate colony (B) and soft-agar experiments (C) were conducted to test for tumorigenicity of PC9 and L78 cells. Bar height corresponds to the mean, and error bars represent SD for three biological replicates. (D and E) The BALB/c nude mice was used to determine the growth of tumor, originating injection of PC9 and L78 cells. Tumor volume was measured every three days, until the end of third week (D). Circle dot on line corresponds to the mean, error bars represent SD for four biological replicates. The tumor grew on the mouse (E, left), extracted tumor tissues from the mouse (E, middle) and pathological section of tumor tissues were (E, right) imaged. (F) The immunohistochemical staining was conducted to determine the protein expression of AGER. Horizontal line in box corresponds to the mean, error bars represent SD for six technical replicates. ${ }^{*} P<0.05,{ }^{* *} P<0.01$, calculated by the student's $t$-test

\subsection{IncAGER possibly actives autophagy}

As AGER has been reported to affect autophagy, ${ }^{23}$ herein we asked whether the IncAGER has a similar function. Levels of autophagy, as indicated by an enhanced LC3-II/LC3I ratio, were significantly higher in PC9 and L78 cells which overexpressed IncAGER when compared to the corresponding control cells (Figure 5A), suggesting that IncAGER may modulate autophagy in these cells.

\subsection{0 | LncAGER has a possible effect on THP-1 induced tumor cytotoxicity}

When co-incubated with THP-1 cells, the results showed that overexpression of IncAGER significantly boosted THP-1's cytotoxic activity against PC9 or L78 cells when compared to control cells $(P<0.01$ for both cells; Figure $5 \mathrm{~B})$. Further, significantly more increases in apoptosis proportion were exhibited in PC9 or L78 cells overexpression IncAGER 
(A)

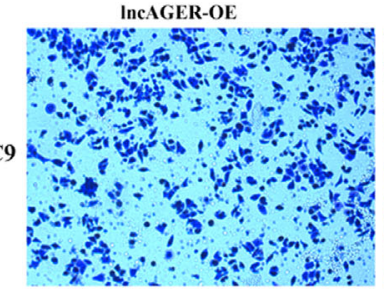

(B)

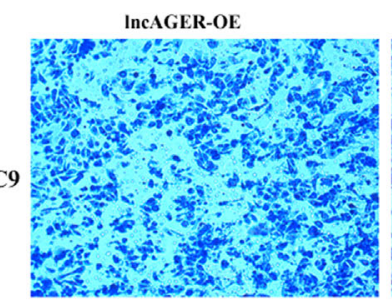

(C)
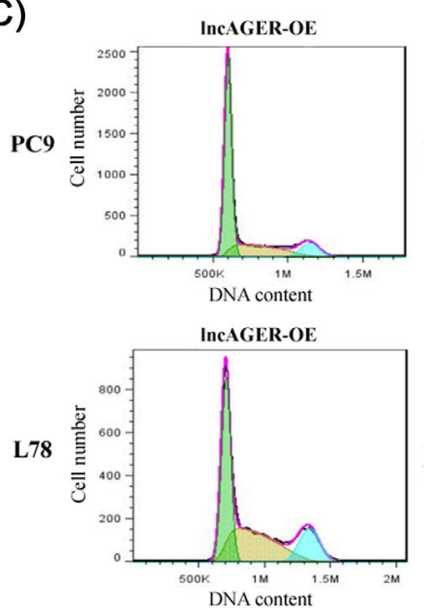

(D)

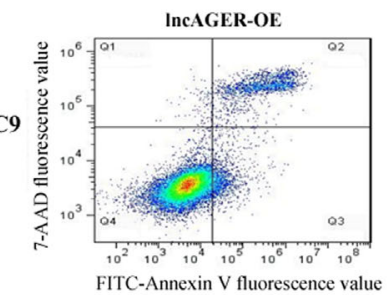

IncAGER-OE

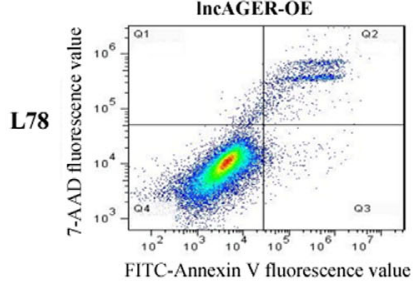

empty-NC

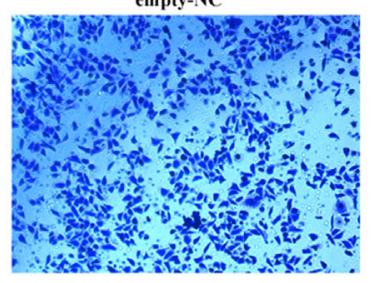

empty-NC
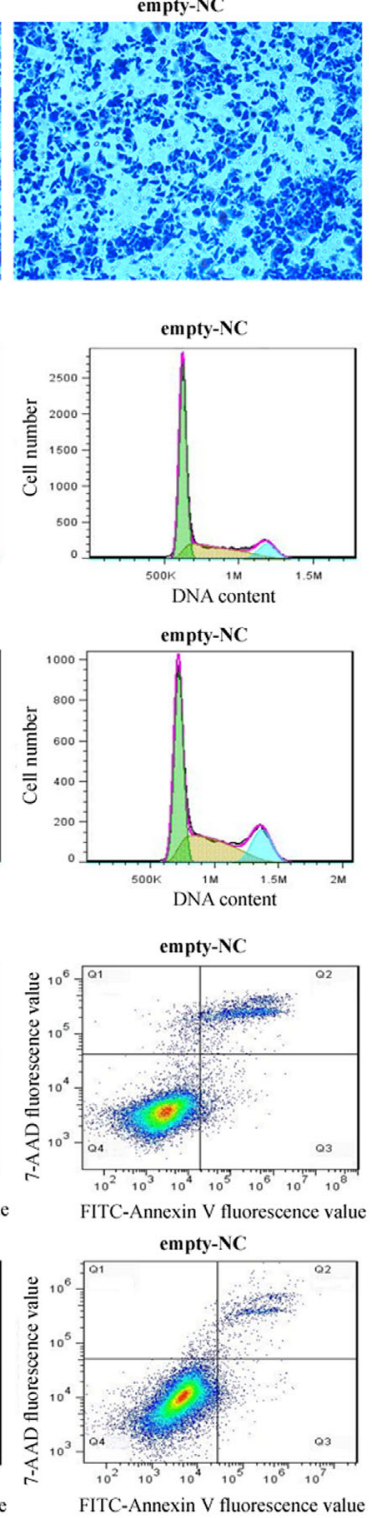
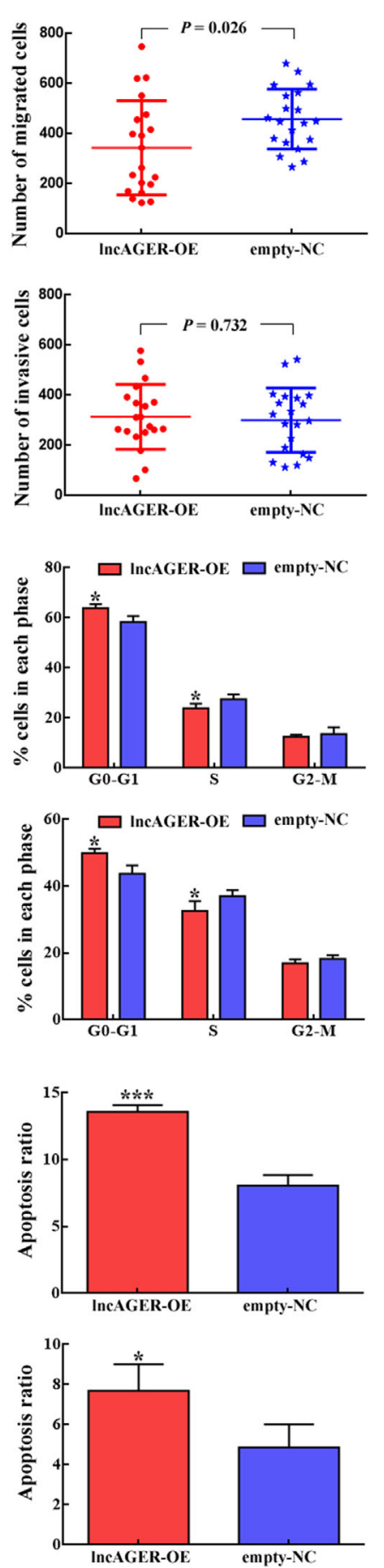

FIGURE 4 Biological effects of IncAGER on cell migration, invasion, cell cycle and apoptosis. (A and B) The Transwell assay was conducted to determine the cell migration (A) and invasion with MatrigelTM coated (B) of PC9 cells. Midcourt line corresponds to the mean, error bars represent SD for three biological replicates. (C) The flow cytometry was conducted to determine the cell cycle of PC9 and L78 cells. (D) The flow cytometry was conducted to determine the cell apoptosis of PC9 and L78 cells. Bar height corresponds to the mean, and error bars represent SD for three biological replicates. ${ }^{*} P<0.05,{ }^{* *} P<0.01,{ }^{* * *} P<0.001$, calculated by the Student's $t$-test 
(A)

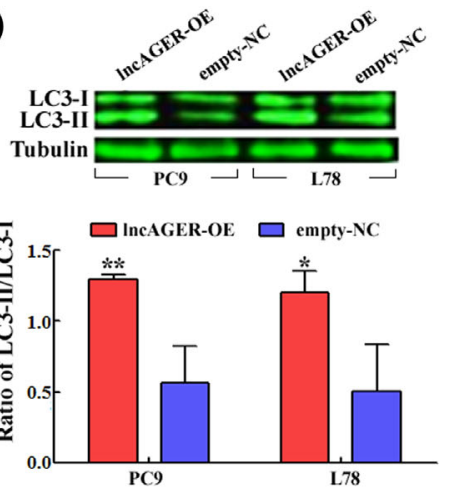

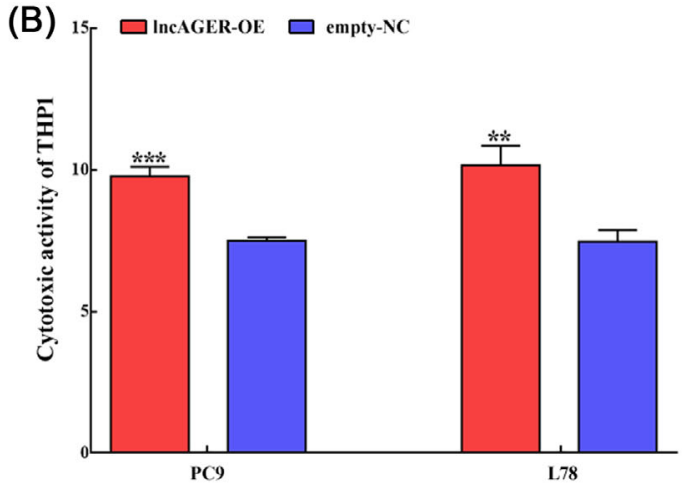

(C)
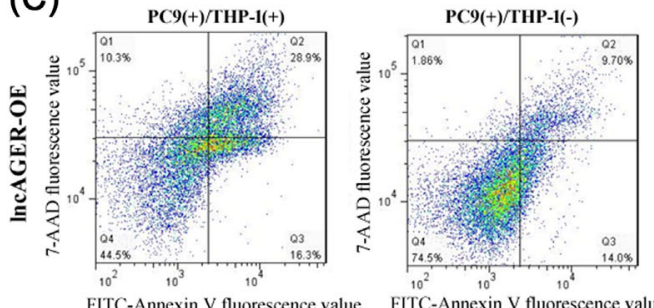

FITC-Annexin $\mathrm{V}$ fluorescence value $\quad$ FITC-Annexin $\mathrm{V}$ fluorescence value
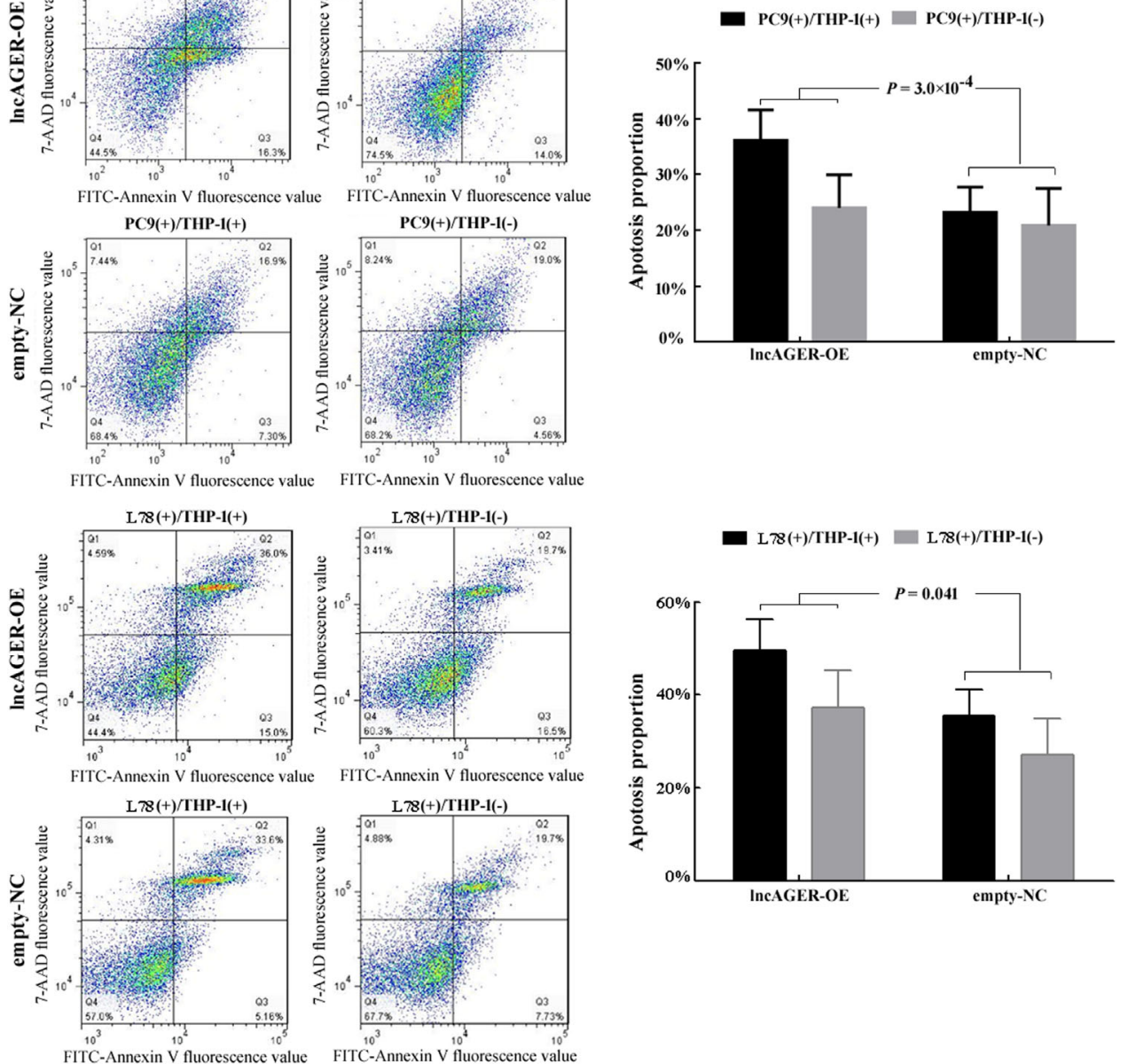

FIGURE 5 Biological effects of IncAGER on autophagy and tumor cytotoxicity of THP-1. (A) The western blot was conducted to determine the expression of LC3-I and LC3-II, the ratio of which indicates the autophagy level in PC9 and L78 cells. (B) The CCK8 assay was conducted to determine the proliferation of PC9 and L78 cells co-cultured with THP1. (C) The flow cytometry was conducted to determine the cell apoptosis of PC9 and L78 cells co-cultured with THP1. Bar height corresponds to the mean, and error bars represent SD for three biological or technical replicates. ${ }^{*} P<0.05,{ }^{* *} P<0.01,{ }^{* * *} P<0.001$, calculated by the Student's $t$-test

than control cells (PC9: $12.5 \%$ vs $2.3 \%$, L78: $13.5 \%$ vs $9.9 \%$; $P$ values equal to $3.00 \times 10^{-4}$ and 0.041 , respectively; Figure $5 \mathrm{C}$ ).

\section{4 | DISCUSSION}

Although many IncRNAs have been linked with lung cancer development, little is known about their roles in tumor immunology. In the current study, we revealed IncAGER modulates the expression of AGER, a critical innate immune PRR, and that it plays a pivotal role in lung cancer. LncAGER is down-regulated in lung cancer tissues owing to hypermethylation and its low expression is correlated with advanced $T$ status in lung cancer patients. Mechanistically, our study shows that IncAGER impairs lung cancer development by affecting proliferation, apoptosis, the cell cycle and lung tumor cell migration. 


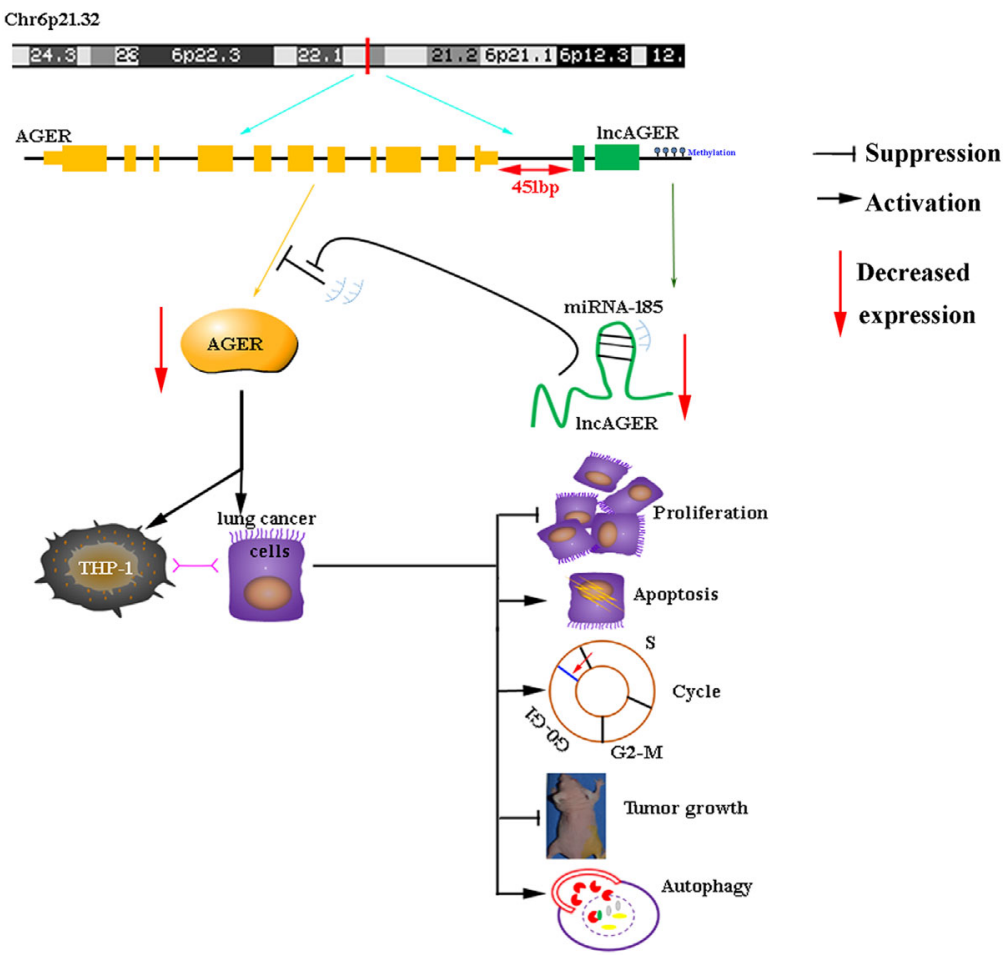

FIGURE 6 Proposed functional action of IncAGER in modulating lung cancer development. Promoter methylation causes decreased LncAGER expression in lung cancer and promotes lung cancer development by downregulating AGER expression, resulting in inactivation of anti-tumor immunity and autophagy, both of which accelerate progress of lung cancer

Furthermore, our study suggests that IncAGER may also functionally conduces to cytotoxic activity of immunologic effector cells and promoted autophagy. Importantly, to our knowledge, our study is the first to explore the role on innate-immune related IncRNAs in lung cancer development.

The IncAGER is a $656 \mathrm{bp}$ transcript without protein-coding potency. It is located on chromosome 6p21.32 (chr6:3215251632153659), $417 \mathrm{bp}$ upstream to the AGER gene. The $6 \mathrm{p} 21.32$ is an identified susceptible region of lung cancer in different ethnicities. ${ }^{24-}$ ${ }^{26}$ Accumulation evidences demonstrated that AGER is related to lung cancer, a pathology that is intimately linked with the innate immune system and inflammation. ${ }^{11,12}$ Specifically, it has been shown that AGER is down-regulated or absent during lung carcinogenesis. ${ }^{11,12}$ Further, GEO chip data (GSE32863, GSE27262) showed that AGER ranks among the top five abnormal coding genes in lung cancer. Further, in contrast as most cancer types wherein AGER expression is up-regulated, ${ }^{27-36}$ in the present study, we also found that AGER was down-regulated in the lung cancer tissues used herein. While AGER is expressed in innate immune cells to enable the recognition of allergens and to active innate immune responses, it is also expressed in epithelial cell such as those which are present in the pulmonary tissue to enable innate immune cells recruitment. ${ }^{27,37,38}$ Notably, genetic variants in the AGER gene have been reported to be associated with lung cancer risk in a Chinese population. ${ }^{39,40}$ Together, these studies suggest that AGER may play a role in anti-lung oncogenesis.

In the current study, we found that IncAGER exerted an inhibitory action on carcinogenesis, similar to that exhibited by
AGER. We found that IncAGER was down-regulated owing to high lever methylation in lung cancer and that the low-expression of IncAGER was correlated with advanced T status. The 5-Aza-CdR treatment could restore IncAGER expression. Hypermethylation in upstream of AGER has been reported to be associated with decreased AGER expression. ${ }^{19}$ On account of IncAGER is located at upstream of $A G E R$, based on our findings, we hold the opinion that this hypermethylation first causes reduced IncAGER expression and followed by AGER decrease owing to IncAGER regulation. Over-expression of IncAGER significantly inhibited cell proliferation of lung cancer cells. LncAGER also induced cell cycle arrest at G0/G1 phase with fewer cells in the $S$ phase, suggesting that IncRNA impairs cell division. Also, we showed that IncAGER promoted cell apoptosis. Specially, ectopic IncAGER expression is sufficient to inhibit migration but not invasion of lung cancer cells. Unlike migration referring motile ability, cell invasion defines the ability of cells to become motile and to navigate through the extracellular matrix within a tissue or to infiltrate neighbouring tissues. This process needs gene expression changes causing proteolysis and degradation of the matrix, ${ }^{41}$ which apparently fail to achieve by IncAGER. Cell invasion is close to cancer metastasis and needs synthesis and secretion of degradation enzymes. This may be why IncAGER expression correlates with $T$ but not $N$ and $M$ in patients.

Furthermore, IncAGER possibly modulates the anti-tumor activities of monocytic THP1 cells wherein the co-cultivation experiments demonstrated that the up-regulation of IncAGER effectively enhanced 
the cytotoxic effects of THP1. LncAGER may also promote autophagy as that the autophagy level was increased in response to IncAGER upregulation. However, additional experiments are required to further explore the role of IncAGER on innate immunity and autophagy.

We propose that IncAGER exerts its inhibitory role on lung cancer in part due to effects on AGER. Underlying the ceRNA mechanism, we propose that IncAGER acts as a miR-185 sequestrate and thereby increases the expression of AGER. MiR185 has been demonstrated to target AGER in esophageal squamous cell carcinomas. ${ }^{33}$ Here, miR-185 was consistently found to target on AGER in lung cancer. Controversially, miR185 is an identified tumor suppressor of several cancers, ${ }^{42-46}$ which has been reported to be involved in chemo-resistance of lung cancer. ${ }^{17}$ Further, miR-185 has been discovered to target AKT1 and ABCC1 to inhibit lung genesis and progression. ${ }^{17,18}$ Here, IncAGER also prevents suppression effect of miR-185 on $A K T 1$ and $A B C C 1$ as same as what it had done on AGER, suggesting that IncAGER has reciprocal effect on lung carcinogenesis. Inconceivably, both $\mathrm{AKT} 1$ and $\mathrm{ABCC} 1$ were reversely downregulated in ectopic IncAGER cells when compared to control cells. This is really confused but probable. It is plausible to speculate that by sponging other microRNAs or regulatory mechanism, IncAGER might also affect expression of other protein coding genes that may have regulatory effect on AKT1 and ABCC1 expression. Anyway, our findings confirm that IncAGER exerts an integrated effect playing as an inhibitory role on lung cancer.

In summary, our present study revealed that IncAGER is downregulated in lung cancer. Upregulation of IncAGER can inhibit lung cancer proliferation and migration, induce cell cycle arrest at $G_{0} / G_{1}$ phase and promote apoptosis. LncAGER also functions in a manner similar to that of its target, AGER, to possibly facilitate tumor immunity and autophagy via up-regulation of AGER by sponging miR-185 (Figure 6). Taken together, these data demonstrate that IncAGER plays an inhibitory role in lung oncogenesis and may be a druggable target or as a drug towards the curtailment of lung cancer.

\section{ACKNOWLEDGMENTS}

This study was supported by the National Natural Scientific Foundation of China grants 81402753, 81672303 (LY) and 81473040, 81673267 (JL). Guangzhou Science and Technology Program Pearl River Nova projects Grant 201710010049 (LY). Guangdong education bureau Characteristic innovation project Grants 2015KTSCX116 (LY) and Guangdong Provincial Major Projects Grants 2014 KZDXM046 (JL). The funders had no role in study design, data collection and analysis, decision to publish, or preparation of the manuscript. We thank Prof. Lan Zhang and Yuanhang Wang for their assistants on autophagy detection.

\section{CONFLICTS OF INTEREST}

The authors declare that they have no competing interests.

\section{AUTHORS' CONTRIBUTIONS}

LY designed the study. ZHP, LL, and WJN performed the most experiments. FMQ and YC scored the AGER expression of IHC data. JBC analyzed the qRT-PCR results. BYY collected the tissue samples. YFZ, $\mathrm{SM}$, and JCL revised the paper writing. LY and ZHP wrote the paper.

\section{ORCID}

Lei Yang (iD http://orcid.org/0000-0002-1315-7651

\section{REFERENCES}

1. Siegel RL, Miller KD, Jemal A. Cancer Statistics, 2017. CA Cancer J Clin. 2017;67:7-30.

2. Chen W, Zheng R, Baade PD, et al. Cancer statistics in China, 2015. CA Cancer J Clin. 2016;66:115-132.

3. Allemani C, Weir HK, Carreira H, et al. Global surveillance of cancer survival 1995-2009: analysis of individual data for 25,676,887 patients from 279 population-based registries in 67 countries (CONCORD-2). Lancet. 2015;385:977-1010.

4. de Mello RA, Veloso AF, Esrom Catarina P, Nadine S, Antoniou G. Potential role of immunotherapy in advanced non-small-cell lung cancer. Onco Targets Ther. 2017;10:21-30.

5. Reck M, Rodriguez-Abreu D, Robinson AG, et al. Pembrolizumab versus chemotherapy for PD-L1-positive non-small-cell lung cancer. N Engl J Med. 2016;375:1823-1833.

6. Borghaei $\mathrm{H}$, Paz-Ares L, Horn L, et al. Nivolumab versus docetaxel in advanced nonsquamous non-small-cell lung cancer. $N$ Engl J Med. 2015;373:1627-1639.

7. Koyama S, Akbay EA, Li YY, et al. Adaptive resistance to therapeutic PD-1 blockade is associated with upregulation of alternative immune checkpoints. Nat Commun. 2016;7:10501.

8. Zaretsky JM, Garcia-Diaz A, Shin DS, et al. Mutations associated with acquired resistance to PD-1 blockade in melanoma. $N$ Engl J Med. 2016;375:819-829.

9. Ibrahim ZA, Armour CL, Phipps S, Sukkar MB. RAGE and TLRs: relatives, friends or neighbours?. Mol Immunol. 2013;56:739-744.

10. Oczypok EA, Milutinovic PS, Alcorn JF, et al. Pulmonary receptor for advanced glycation end-products promotes asthma pathogenesis through IL-33 and accumulation of group 2 innate lymphoid cells. J Allergy Clin Immunol. 2015;136:747-756. e744.

11. Wang H, Li Y, Yu W, Ma L, Ji X, Xiao W. Expression of the receptor for advanced glycation end-products and frequency of polymorphism in lung cancer. Oncol Lett. 2015;10:51-60.

12. Rho JH, Roehrl MH, Wang JY. Glycoproteomic analysis of human lung adenocarcinomas using glycoarrays and tandem mass spectrometry: differential expression and glycosylation patterns of vimentin and fetuin A isoforms. Protein J. 2009;28:148-160.

13. Gutschner T, Hammerle M, Eissmann $M$, et al. The noncoding RNA MALAT1 is a critical regulator of the metastasis phenotype of lung cancer cells. Cancer Res. 2013;73:1180-1189.

14. Liu Y, Luo F, Xu Y, et al. Epithelial-mesenchymal transition and cancer stem cells, mediated by a long non-coding RNA, HOTAIR, are involved in cell malignant transformation induced by cigarette smoke extract. Toxicol Appl Pharmacol. 2015;282:9-19.

15. Terashima M, Tange S, Ishimura A, Suzuki T. MEG3 long noncoding RNA contributes to the epigenetic regulation of epithelial-Mesenchymal transition in lung cancer cell lines. J Biol Chem. 2017;292:82-99.

16. Jiang $\mathrm{W}$, Zhang $\mathrm{D}, \mathrm{Xu} \mathrm{B}$, et al. Long non-coding RNA BANCR promotes proliferation and migration of lung carcinoma via MAPK pathways. Biomed Pharmacother. 2015;69:90-95. 
17. Pei K, Zhu JJ, Wang CE, Xie QL, Guo JY. MicroRNA-185-5p modulates chemosensitivity of human non-small cell lung cancer to cisplatin via targeting ABCC1. Eur Rev Med Pharmacol Sci. 2016;20:4697-4704.

18. Li S, Ma Y, Hou X, et al. MiR-185 acts as a tumor suppressor by targeting AKT1 in non-small cell lung cancer cells. Int J Clin Exp Pathol. 2015;8:11854-11862.

19. Mullapudi N, Ye B, Suzuki M, et al. Genome wide methylome alterations in lung cancer. PLoS ONE. 2015;10:e0143826.

20. Yang L, Yang X, Ji W, et al. Effects of a functional variant c.353T $>\mathrm{C}$ in snai1 on risk of two contextual diseases. Chronic obstructive pulmonary disease and lung cancer. Am J Respir Crit Care Med. 2014;189:139-148.

21. Ribeiro-Dias F, Marzagao Barbuto JA, Tsujita M, Jancar S. Discrimination between NK and LAK cytotoxic activities of murine spleen cells by MTT assay: differential inhibition by PGE(2) and EDTA. J Immunol Methods. 2000;241:121-129.

22. Denton D, Xu T, Kumar S. Autophagy as a pro-death pathway. Immunol Cell Biol. 2015;93:35-42.

23. Verma N, Manna SK. Advanced glycation end products (AGE) potently induce autophagy through activation of RAF protein kinase and nuclear factor kappaB (NF-kappaB). J Biol Chem. 2016;291:1481-1491.

24. Shiraishi K, Okada Y, Takahashi A, et al. Association of variations in HLA class II and other loci with susceptibility to EGFR-mutated lung adenocarcinoma. Nat Commun. 2016;7:12451.

25. Hosgood HD, 3rd, Song M, Hsiung CA, et al. Interactions between household air pollution and GWAS-identified lung cancer susceptibility markers in the Female Lung Cancer Consortium in Asia (FLCCA). Hum Genet. 2015;134:333-341.

26. Lan Q, Hsiung CA, Matsuo K, et al. Genome-wide association analysis identifies new lung cancer susceptibility loci in never-smoking women in Asia. Nat Genet. 2012;44:1330-1335.

27. Nasser MW, Wani NA, Ahirwar DK, et al. RAGE mediates S100A7induced breast cancer growth and metastasis by modulating the tumor microenvironment. Cancer Res. 2015;75:974-985.

28. Gebhardt C, Riehl A, Durchdewald M, et al. RAGE signaling sustains inflammation and promotes tumor development. J Exp Med. 2008;205:275-285.

29. Taguchi A, Blood DC, del Toro G, et al. Blockade of RAGE-amphoterin signalling suppresses tumour growth and metastases. Nature. 2000;405:354-360

30. Zhang Q, Jin Y, Zhao CF, Wang WJ, Liu GY. Receptor for advanced glycation end-products (RAGE) is overexpressed in human osteosarcoma and promotes the proliferation of osteosarcoma U-2OS cells in vitro. Genet Mol Res. 2016;15. https://doi.org//10.10.4238/gmr. 15027817

31. Sakellariou S, Fragkou P, Levidou G, et al. Clinical significance of AGERAGE axis in colorectal cancer: associations with glyoxalase-I, adiponectin receptor expression and prognosis. BMC Cancer. 2016; 16:174.

32. Zheng L, Li D, Zhou YM, Yang H, Cheng D, Ma XX. Effects of receptor for advanced glycation endproducts on microvessel formation in endometrial cancer. BMC Cancer. 2016;16:93.

33. Jing $\mathrm{R}$, Chen $\mathrm{W}$, Wang $\mathrm{H}$, et al. Plasma miR-185 is decreased in patients with esophageal squamous cell carcinoma and might suppress tumor migration and invasion by targeting RAGE. Am J Physiol Gastrointest Liver Physiol. 2015;309:G719-G729.
34. Qie GQ, Wang CT, Chu YF, Wang R. Expression of HMGB1/RAGE protein in renal carcinoma and its clinical significance. Int J Clin Exp Pathol. 2015;8:6262-6268.

35. Wagner NB, Weide B, Reith M, et al. Diminished levels of the soluble form of RAGE are related to poor survival in malignant melanoma. Int J Cancer. 2015;137:2607-2617.

36. Xu XC, Abuduhadeer X, Zhang WB, Li T, Gao H, Wang YH. Knockdown of RAGE inhibits growth and invasion of gastric cancer cells. Eur J Histochem. 2013;57:e36.

37. van Zoelen MA, Achouiti A, van der Poll T. RAGE during infectious diseases. Front Biosci (Schol Ed). 2011;3:1119-1132.

38. Parmley LA, Elkins ND, Fini MA, Liu YE, Repine JE, Wright RM. Alpha4/beta-1 and alpha-L/beta- 2 integrins mediate cytokine induced lung leukocyte-epithelial adhesion and injury. $\mathrm{Br} J$ Pharmacol. 2007;152:915-929.

39. Pan H, Niu W, He L, et al. Contributory role of five common polymorphisms of RAGE and APE1 genes in lung cancer among Han Chinese. PLOS ONE. 2013;8:e69018.

40. Wang $\mathrm{X}$, Cui $\mathrm{E}$, Zeng $\mathrm{H}$, et al. RAGE genetic polymorphisms are associated with risk, chemotherapy response and prognosis in patients with advanced NSCLC. PLoS ONE. 2012;7:e43734.

41. Friedl $P$, Wolf $K$. Tumour-cell invasion and migration: diversity and escape mechanisms. Nat Rev Cancer. 2003;3:362-374.

42. Tang H, Liu P, Yang L, et al. MiR-185 suppresses tumor proliferation by directly targeting E2F6 and DNMT1 and indirectly upregulating BRCA1 in triple-negative breast cancer. Mol Cancer Ther. 2014;13:3185-3197.

43. Zhang Z, Liu X, Feng B, et al. STIM1, a direct target of microRNA-185, promotes tumor metastasis and is associated with poor prognosis in colorectal cancer. Oncogene. 2015;34:4808-4820.

44. Zhou X, Zhu W, Li H, et al. Diagnostic value of a plasma microRNA signature in gastric cancer: a microRNA expression analysis. Sci Rep. 2015;5:11251.

45. Qiu F, Xiong JP, Deng J, Xiang XJ. TRIM29 functions as an oncogene in gastric cancer and is regulated by miR-185. Int J Clin Exp Pathol. 2015;8:5053-5061.

46. Dong-Xu W, Jia L, Su-Juan Z. MicroRNA-185 is a novel tumor suppressor by negatively modulating the $\mathrm{Wnt} /$ beta-catenin pathway in human colorectal cancer. Indian J Cancer. 2015;52:E182-E185.

\section{SUPPORTING INFORMATION}

Additional Supporting Information may be found online in the supporting information tab for this article.

How to cite this article: Pan Z, Liu L, Nie W, et al. Long noncoding RNA AGER-1 functionally upregulates the innate immunity gene AGER and approximates its anti-tumor effect in lung cancer. Molecular Carcinogenesis. 2018;57:305-318. https://doi.org/10.1002/mc.22756 